\title{
IPTEKS BAGI MASYARAKAT KELOMPOK USAHA TANI AGRO JAMUR MA'ISYATANA MADIUN
}

\author{
Oleh: \\ Supari Muslim ${ }^{1}$, Asrul Bahar ${ }^{2}$, Nita Kusumawati ${ }^{3}$ \\ 1Jurusan Teknik Elektro FT Unesa \\ ${ }^{2}$ Jurusan Pendidikan Kesejahteraan Keluarga FT Unesa \\ 3 Jurusan Kimia FMIPA Unesa \\ ${ }^{1}$ suparimuslim@gmail.com \\ 2asrulbahar96@yahoo.com \\ 3nitakusumawati82@yahoo.com
}

\begin{abstract}
Abstrak
Secara umum, kegiatan ini bertujuan untuk meningkatkan pendapatan usaha budidaya jamur tiram yang dikembangkan oleh Agro Jamur Ma'isyatana (AJM) Madiun. Secara lebih khusus, kegiatan ini diarahkan untuk dapat meningkatkan produktivitas dan minimalisasi gagal panen pada budidaya jamur tiram, melalui introduksi teknologi, khususnya pada tahapan sterilisasi medium tanam (baglog) jamur tiram. Selain itu, pada kegiatan ini juga telah dilakukan upaya pembuatan Standar Operasional Prosedur (SOP) budidaya jamur tiram dengan teknologi sederhana. Introduksi teknologi pada tahapan sterilisasi baglog jamur tiram telah dilakukan melalui introduksi mesin boiler sterilisator. Melalui introduksi mesin boiler - sterilisator, didapatkan peningkatan kapasitas produksi jamur tiram sebesar $100 \%$, dimana dengan menggunakan drum bekas, proses sterilisasi dapat dilakukan terhadap 100 buah baglog per proses. Sementara, setelah menggunakan mesin boiler-sterilisator, proses sterilisasi dapat dilakukan terhadap 200 buah baglog per proses.
\end{abstract}

Kata Kunci:Jamur Tiram, Boiler, Sterilisator

\section{Abstract}

In general, this activity aims to increase the income of the oyster mushroom cultivation business developed by Agro Jamur Ma'isyatana (AJM) Madiun. More specifically, this activity is directed to increase productivity and minimize crop failure on oyster mushroom cultivation, through the introduction of technology, especially on the stages of oyster mushrooms planting medium (baglog) sterilization. In addition, in this event also has made efforts on manufacture of Standard Operating Procedures (SOP) for oyster mushroom cultivation with simple technology. Introduction of technology at stage of oyster mushroom planting medium sterilization has been done through the introduction of boiler and sterilizer machine. Through the introduction of boiler and sterilizer machine, obtained an increase in the production capacity of oyster mushrooms by $100 \%$, where by the use of drums, the sterilization process can be carried out on 100 pieces baglog per process. Meanwhile, after using the boiler and sterilizer machine, the sterilization process can be carried out on 200 baglog per process.

Keywords: Oyster mushroom, boiler, sterilizer

\section{PENDAHULUAN}

Kini usaha jamur tiram makin menjamur, karena mudahnya cara budidaya jamur tiram, harga jual yang stabil serta permintaan yang terus meningkat menjadi salah satu faktor banyaknya bermunculan petani jamur tiram. Penampilannya yang putih bersih dan menarik menjadi daya tarik tersendiri. Rasanya juga sangat enak, hampir seperti "daging ayam". Meningkatnya minat masyarakat untuk mengkonsumsi jamur merupakan salah satu peluang bagus untuk memulai usaha tani jamur konsumsi (Achmad, dkk., 2011).

Perkembangan usaha jamur konsumsi pun kini sudah sangat pesat, misalnya saja jamur yang banyak diminati konsumen antara lain jamur tiram putih (Pleurotus ostreatus), jamur kuping (Auricularia polytricha), jamur merang (Volvariella volvaceae), dan jamur shiitake (Lentinus edodes) (Parjimo dan Andoko, 2010). Munculnya jamur konsumsi, dapat dijadikan sebagai salah satu alternatif dalam mengatasi masalah kekurangan pangan dan gizi yang ada saat ini. Karena berdasarkan penelitian, kandungan mineral 
pada jamur lebih tinggi daripada daging sapi atau domba, bahkan hampir dua kali lipat jumlah garam mineral dalam sayuran (Sunarmi dan Saparinto, 2010).

Salah satu daerah di Jawa Timur yang saat ini sedang "getol" mengembangkan usaha jamur di wilayahnya adalah Kabupaten Madiun. Di Kabupaten Madiun terdapat 2 pengusaha jamur yang tergolong besar, yaitu AJISAKA Jamur yang berlokasi di Kecamatan Jiwan Kabupaten Madiun dan Agro Jamur Ma'isyatana yang berlokasi di Kecamatan Geger Kabupaten Madiun. Tidak hanya pengusaha skala besar, di daerah ini juga banyak petani-petani jamur yang masih dalam skala kecil.

Agro Jamur Ma'isyatana adalah kelompok usaha tani jamur yang berdiri sejak tanggal 27 Mei 2006. Kelompok usaha tani Agro Jamur Ma'isyatana berlokasi di Desa Singgahan Kecamatan Kebonsari Kabupaten Madiun. Namun, karena sesuatu hal, maka mulai tanggal 10 Januari 2008 pusat kegiatan dipindahkan ke desa Purworejo Kecamatan geger Kabupaten Madiun. Agro Jamur Ma'isyatana (AJM) merupakan bentuk kegiatan usaha yang berhubungan dengan jamur. Selama ini, AJM telah memberikan layanan berupa penyediaan seluruh komponen budidaya jamur tiram, melayani pemesanan media tanam (baglog) jamur, menyediakan bibit jamur, mengedarkan (memasarkan) dan menampung jamur hasil budidaya, serta pembinaan terhadap petani jamur. Hingga saat ini, jumlah anggota AJM telah mencapai \pm 60 orang, yang tersebar di berbagai daerah seperti Madiun, Ponorogo, Magetan, Bojonegoro, Blora, Riau, dan Kalimantan. Dari sekitar 60 petani jamur yang tergabung dengan AJM, sebagian besar, yaitu sebanyak $83 \%$ atau sebanyak 50 petani jamur berproduksi di Kabupaten Madiun. Dari 50 petani jamur ini, ada yang produktif dan bahkan sangat produktif, namun ada juga yang tidak produktif.

Dengan kemajuannya yang terbilang relatif pesat, AJM telah ditunjuk oleh Dinas Perindustrian dan Perdagangan Provinsi Jawa Timur untuk berperan menjadi tutor pengembangan usaha jamur di wilayah Kabupaten Madiun menggantikan AJISAKA Jamur yang berlokasi di Kecamatan Jiwan Madiun, yang selama ini merupakan kompetitor terkuat dari kelompok usaha tani ini. Bagaimanapun, kendala kuat yang menghambat pengembangan usaha dari kelompok usaha tani Agro Jamur Ma'isyatana ini adalah masalah permodalan yang terbatas. Hal ini pulalah yang kemudian menyebabkan terbatasnya penggunaan peralatan canggih dalam proses produksinya.

Selama ini, proses pembuatan media tanam (baglog) dan budidaya jamur tiram yang dilakukan oleh kelompok usaha tani Agro Jamur Ma'isyatana ini masih banyak menggunakan peralatan konvensional, seperti sekop untuk mengaduk dan mencampur adonan media tanam sebelum difermentasi, cetok untuk mengisikan adonan media tanam ke dalam kantung plastik yang disertai penekanan/pengepresan secara manual menggunakan tangan pekerja, serta proses sterilisasi yang hanya dilakukan dengan menggunakan bejana sterilisasi dari bahan drum bekas. Penggunaan peralatan sederhana tersebut, terutama pada proses sterilisasi, telah menyebabkan terkontaminasinya $20 \%$ baglog (media tanam) jamur oleh berbagai macam mikroba dan jamur liar yang dapat mengganggu pertumbuhan jamur tiram dan menyebabkan resiko gagal panen sebesar $20 \%$ tiap kali panen.

Kendala peralatan yang masih tradisional telah membuat kapasitas produksi jamur kelompok usaha tani AJM masih terbatas. Padahal selama ini berdasarkan data dari Dinas Perindustrian dan Perdagangan Kabupaten Madiun, peluang pasar yang ada masih sangat besar karena dengan kapasitas produksi media tanam yang mencapai 10.000 buah dan jamur segar sebanyak $1.000 \mathrm{~kg}$ per bulan tersebut, ternyata baru mampu memenuhi $10 \%$ permintaan pasar. Oleh karena itu, diperlukan perbaikan proses budidaya jamur dan teknologi yang terlibat di dalamnya untuk dapat meningkatkan kapasitas produksi jamur dan mengeliminasi jumlah jamur yang rusak setiap kali panen, sehingga akan dapat menambah penghasilan dan kesejahteraan para anggotanya.

\section{METODE PELAKSANAAN}

\section{Bahan dan Peralatan}

Bahan dan peralatan yang digunakan pada kegiatan ini meliputi: plat stainless steel (ketebalan $2 \mathrm{~mm}$ dan $4 \mathrm{~mm}$ ), rangkaian elektronika, pisau potong, mur dan baut (ø10 $\mathrm{mm}$ ), pipa фp $8 \mathrm{~cm}$, pipa op $4 \mathrm{~cm}$, pipa o 14 $\mathrm{cm}$, pipa op $18 \mathrm{~cm}$, mata bor dan gerinda HSS-R/DIN 1-10 mm, dan mata gergaji besi (Grid kasar 18 \& Grid halus 24). 


\section{Prosedur Kerja}

Pada Gambar 1 tampak desain rangkaian boiler-sterilisator, dimana boiler akan memproduksi uap panas yang digunakan untuk sterilisasi baglog jamur tiram yang terdapat dalam ruang sterilisator. Sementara itu, rancang bangun boiler dilakukan dengan menggunakan desain seperti yang tampak pada Gambar 2 dan rancang bangun sterilisator dilakukan dengan menggunakan desain seperti yang tampak pada Gambar 3.

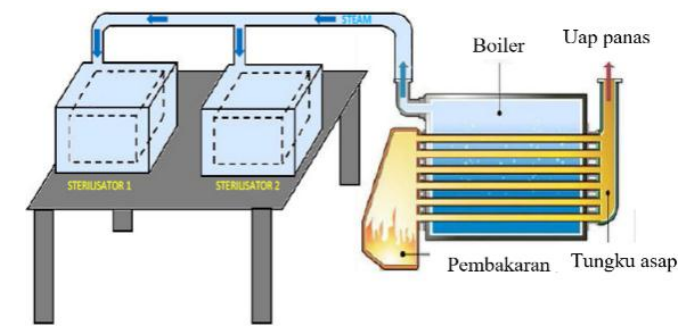

Gambar 1. Rangkaian alat boiler-sterilisator untuk sterilisasi baglog jamur

Alat ini terdiri dari dua bagian, yaitu sterilisator dan boiler dimana sterilisator bekerja dengan memanfaatkan steam/ pemanasan dari boiler yang selanjutnya akan digunakan untuk proses sterilisasi baglog jamur.

\section{Sterilisator}

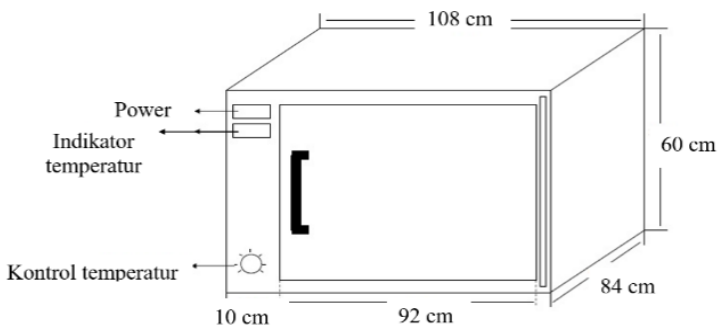

Gambar 2. Desain alat sterilisator

\section{Keterangan:}

Bahan yang digunakan dalam pembuatan sterilisator ini adalah plat $8 \mathrm{~mm}$ dimaksudkan agar steam tidak keluar dan stabil didalam sterilisator.

\section{Boiler}

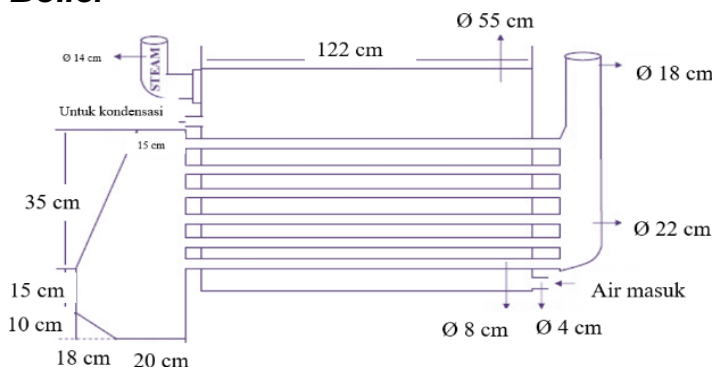

Gambar 3. Desain alat boiler
Keterangan:

Pada dinding boiler tersebut digunakan plat dengan ketebalan $10 \mathrm{~mm}$ dimaksudkan agar tahan terhadap panas dari steam maupun dari pipa pemanas. Boiler dengan konstruksi seperti pada gambar 3 di atas termasuk ke dalam type Fire Tube dimana proses pengapian terjadi didalam pipa, kemudian panas yang dihasilkan dihantarkan langsung kedalam boiler yang berisi air. Besar dan konstruksi boiler mempengaruhi kapasitas dan tekanan yang dihasilkan boiler tersebut dan dalam hal ini sesuai dengan konstruksi di atas, tekanan operasi steam hanya terbatas untuk tekanan rendah sekitar 18 bar.

\section{HASIL DAN PEMBAHASAN}

Agro Jamur Ma'isyatana merupakan kelompok usaha jamur yang memiliki sekitar kurang lebih 60 anggota petani jamur, yang tersebar di beberapa daerah seperti Madiun, Ponorogo, Magetan, Bojonegoro, Blora, Riau, dan Kalimantan. Dari sekian banyak anggota tersebut, Agro Jamur Ma'isyatana Gabel pimpinan Nurul Fathoni dan Aneka Aini pimpinan Maskur Arifin lah yang memiliki kapasitas produksi yang paling besar. Dari total produksi 10.000 media tanam (baglog) jamur dan $1.000 \mathrm{~kg}$ jamur segar yang dihasilkan tiap bulan oleh 60 petani jamur yang tergabung dalam Agro jamur Ma'isyatana, kelompok usaha tani Agro Jamur Ma'isyatana mampu memproduksi 5.000 media tanam dan $500 \mathrm{~kg}$ jamur tiram per bulannya. Sementara Aneka Aini mampu memproduksi 3.000-3.500 media tanam (baglog) jamur setiap bulannya.

Cuaca merupakan salah satu faktor yang berpengaruh terhadap kapasitas produksi jamur, dimana suhu udara dan kelembaban yang teratur, sangat diperlukan untuk produksi jamur (Suriawiria, 2002). Disamping cuaca, peralatan yang digunakan dalam pembudidayaan jamur merupakan faktor teknis yang memegang peranan paling penting dan sangat menentukan terhadap kualitas dan kuantitas produksi jamur (Sumarsih, 2010). Hal inilah yang juga menyebabkan kapasitas produksi jamur AJM masih terbatas, terutama pada proses sterilisasi baglog yang seringkali tidak berjalan optimal karena selama ini masih menggunakan bejana yang terbuat dari drum bekas.

Sterilisasi dengan cara ini kurang berhasil, sehingga kurang lebih $20 \%$ baglog terkena kontaminasi jamur liar. Kegagalan sterilisasi 
dengan cara seperti tersebut di atas, antara lain disebabkan oleh hal-hal sebagai berikut: (a) temperatur yang diperlukan, yaitu temperatur $>95{ }^{\circ} \mathrm{C}$, tidak tercapai atau tidak tersebar merata ke setiap baglog yang berada di dalam drum; (b) waktu pemanasan terlalu singkat, rata-rata $<5$ jam, sehingga bibit jamur liar yang terdapat di dalam baglog dalam spora tidak mati; dan (c) tekanan uap air panas yang diperlukan tidak tercapai sehingga banyak jasad kontaminan (berbentuk spora jamur) akan tumbuh. Nilai kontaminasi yang sebesar $20 \%$ tentu saja merupakan kerugian yang sangat besar. Jika baglog yang disterilkan lebih dari 1000 buah, maka jumlah yang terkontaminasi akan mencapai 200 buah.

Pada pembuatan substrat tanam jamur, langkah-langkah yang dilakukan adalah: (1) pencampuran bahan dan pengomposan; (2) pengisian atau pencetakan; (3) sterilisasi atau pasteurisasi; (4) penanaman bibit jamur; dan (5) pemeliharaan. Tahapan sterilisasi baglog jamur merupakan salah satu tahapan budidaya yang paling menentukan keberhasilan budidaya. Hal ini dikarenakan bahan baku substrat tanam jamur banyak mengandung mikroba, terutama jamur liar. Jika substrat tersebut digunakan untuk menanam jamur tanpa melalui proses sterilisasi atau pasteurisasi sebelumnya, kemungkinan besar jamur liar yang tidak diharapkan akan lebih dahulu tumbuh, dan menghambat pertumbuhan jamur yang ditanam. Karena itu, sterilisasi untuk membebaskan substrat tanam jamur dari kontaminan ataupun mikroba lainnya merupakan keharusan. Adapun sterilisasi atau pasteurisasi bertujuan untuk mencegah pertumbuhan semua jasad hidup yang berada di dalam substrat tanam (yang mungkin terbawa bahan baku), yang dapat mengganggu pertumbuhan jamur yang ditanam.

Sterilisasi dapat dilakukan dengan beberapa cara, misalnya dengan udara panas, atau dengan tekanan tinggi, dan sebagainya. Sterilisasi substrat tanam jamur dilakukan dengan menggunakan uap air panas bertekanan tinggi, yaitu pada temperatur uap air sekitar $95-100{ }^{\circ} \mathrm{C}$ dan tekanan 2-3 atm selama 4 jam. Setelah sterilisasi, bahan didiamkan atau disimpan selama 3-4 hari, untuk mengamati ada/tidaknya kontaminasi.

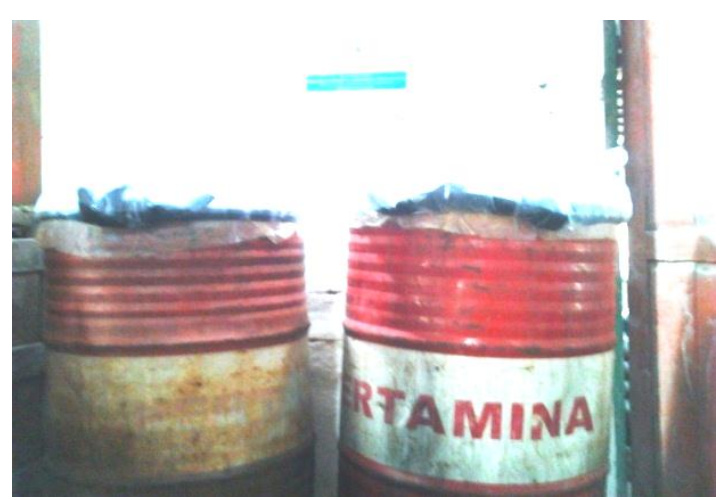

Gambar 4. Peralatan sterilisator dari bahan drum bekas

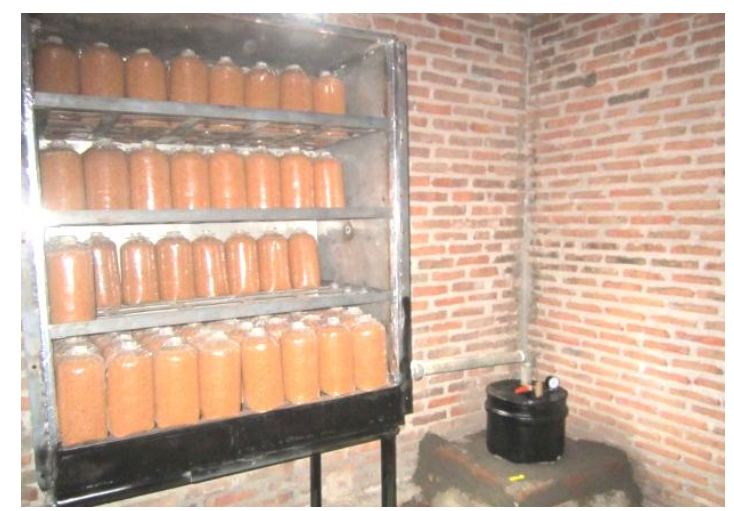

Gambar 5. Boiler-sterilisator baglog jamur

Selama ini, untuk keperluan sterilisasi, kelompok tani Agro Jamur Ma'isyatana membuat sendiri bejana sterilisasi secara sederhana. Bejana tersebut dibuat dari drum bekas dengan volume 500 L. Sterilisasi seperti ini ternyata seringkali kurang berhasil, terbukti dari adanya $20 \%$ substrat tanam (baglog) yang terkena kontaminasi jamur liar yang tidak diharapkan. Nilai kontaminasi yang kurang lebih berkisar $20 \%$ tentu saja merupakan kerugian yang sangat besar. Jika jumlah baglog (substrat tanam) yang disterilkan adalah 1.000 buah, maka jumlah yang terkontaminasi adalah kurang lebih sebesar 200 buah. Untuk mengatasi hal tersebut, maka melalui kegiatan ini telah diintroduksikan penggunaan boiler-sterilisator untuk menekan kontaminasi baglog. Pada gambar 4 dan gambar 5 merupakan tahapan sterilisasi baglog jamur ketika menggunakan drum bekas dan ketika menggunakan peralatan boiler-sterilisator.

\section{SIMPULAN DAN SARAN}

Berdasarkan hasil dari kegiatan yang telah dilakukan, dapat diambil kesimpulan bahwa melalui introduksi mesin boiler - sterilisator, yang dilakukan untuk perbaikan sterilisasi 
baglog jamur, didapatkan peningkatan kapasitas produksi jamur tiram sebesar $100 \%$, dimana dengan menggunakan drum bekas, proses sterilisasi dapat dilakukan terhadap 100 buah baglog per proses. Sementara setelah menggunakan mesin boiler-sterilisator, proses sterilisasi dapat dilakukan terhadap 200 buah baglog per proses. Selain itu, pemanfaatan boiler dan sterilisator dalam proses sterilisasi baglog jamur, telah mampu menekan tingkat kegagalan panen dari $20 \%$ menjadi $9 \%$.

Perbaikan sistem sterilisasi baglog jamur tiram bukanlah satu-satunya tahapan proses budidaya jamur tiram yang harus dioptimalisasi dalam rangka untuk menekan tingkat kegagalan jamur tiram. Hal ini terbukti dengan terdeteksinya tingkat kegagalan panen sebesar $9 \%$, meski telah dilakukan perbaikan pada proses sterilisasi baglog jamur. Oleh karena itu, pada kegiatan selanjutnya, perlu untuk dilakukan perbaikan terhadap proses sterilisasi bibit jamur yang hendak ditebarkan ke dalam baglog jamur, dalam rangka untuk semakin menekan tingkat kegagalan panen jamur tiram hingga $<5 \%$.

\section{DAFTAR PUSTAKA}

Achmad, Mugiono, Arlianti, T., Azmi, C. 2011. Panduan Lengkap Jamur. Penebar Swadaya, Jakarta.

Parjimo, H., dan Andoko, A. 2010. Budi Daya Jamur: Jamur Kuping, Jamur Tiram, dan Jamur Merang. Agro Media Pustaka, Jakarta.

Sumarsih, Sri. 2010. Untung Besar Usaha Bibit Jamur Tiram. Penebar Swadaya, Jakarta.

Sunarmi, Y.I., dan Saparinto, C. 2010. Usaha 6 Jenis Jamur Skala Rumah Tangga. Penebar Swadaya, Jakarta.

Suriawiria, H.U. 2002. Budi Daya Jamur Tiram. Kanisius, Yogyakarta. 